\title{
O lugar de Augusto dos Anjos na poesia brasileira
}

\author{
Nara Marley Aléssio Rubert*
}

\begin{abstract}
Resumo: Trata-se de uma análise sobre a controversa classificação do poeta Augusto dos Anjos, que oscila entre o Simbolismo, Parnasianismo, Romantismo, Cientificismo, Modernismo e até mesmo Surrealismo, a partir de aspectos de sua poesia que apontam para as diversas tentativas de enquadramento de sua obra. Acrescenta-se ainda que sua carreira como professor e escritor, bem como a publicação de sua única obra, "Eu", se deu no período chamado Pré-Modernismo, no início do século passado. A partir disso, avaliam-se alguns traços da sua época, da estética literária de seu tempo e da maneira como isso se mostra ou não em seus poemas. Há aspectos insistentes na obra de Augusto dos Anjos que indicam uma direção para sua leitura: a obsessão pela decomposição, o "irrealizado", a combinação de expressões eruditas com expressões ditas de mau-gosto e, muito especialmente, a morte.
\end{abstract}

Palavras chave: Poesia; Pré-Modernismo; morte.

\begin{abstract}
The aim of this work is to analyze the controversial classification of the poet Augusto dos Anjos, be it Symbolism, Parnassianism, Romanticism, Scientificism, Modernism and even Surrealism, from the aspects of his poetry which point to several attempts to place his work. In addition to this, his career as a professor and writer, as well as the publication of his only work, "Eu", took place in a period called Pre-Modernism, in the beginning of last century. Based on these facts, some features of his time and the literary esthetics of his time are evaluated to see how they are present or not in his poems. There are prevailing aspects in the work of Augusto dos Anjos that direct the reading: the obsession for the decay, the "unrealized", the combination of erudite expressions with vulgar words and, very specially, death.
\end{abstract}

Keywords: Poetry; Pre-Modernism; death.

\section{Características e Temas}

Os estudos de Augusto dos Anjos dividem-se geralmente em torno de crítica biográfica, psicológica e crítica psicanalítica.

A análise baseada na relação vida-obra, lançada pelo francês Sainte Beuve na época do Romantismo, mostra-se frágil e até contraditória. Ressaltar a gestação, a infância, a hereditariedade, o físico, o ambiente e até os ancestrais do autor restringe-nos a uma leitura sempre na mesma direção.

A crítica psicanalítica também não dá conta da análise, pois não se trata de abordar a obra-de-arte em nome da teoria freudiana, mas de colocá-la na posição do analista e o que

\footnotetext{
* Nara Marley Aléssio Rubert é, atualmente, professora de Literatura Brasileira no Centro de Ensino Médio da UPF (Universidade de Passo Fundo) e Colégio São José de Erechim (RS). Sua formação em Letras iniciou em 1988 com a graduação pela UNICRUZ - Universidade de Cruz Alta (RS). Posteriormente, fez duas especializações, uma em 1990, intitulada Especialização em Produção Textual pela UNICRUZ/ UFSM (RS), e outra em 1997, intitulada Especialização em Arte Literária pela ULBRA - Canoas (RS). Concluiu o curso de Mestrado, em 2003, em Literatura Brasileira pela UFRGS e, em 2006, ingressou no curso de Doutorado pela mesma Instituição.
} 
dela se lê na posição da "fala" do analisado, "não importando em nome do que esta fala se sustente" (FERREIRA,1984, p.125).

É comum buscar-se, em experiências de sua vida, dados que justifiquem a abordagem temática e a opção vocabular deste poeta, afinal não é nas características do momento literário chamado Pré-Modernismo, quando surgiu $E u$, onde se podem encontrar essas respostas.

Seja qual for a abordagem ou a escola literária que for usada como base de análise para a obra de A. dos A., ela fornecerá resposta parciais.

Optou-se pelo caminho mais simples, deixar a obra e quem já discutiu muito sobre ela, falar, e, a partir disso buscar referências teóricas sobre qual o melhor enquadramento para esses dados recolhidos.

Ivan Cavalcanti Proença (1980, p. 14) apresenta como incidências recorrentes na obra de Augusto dos Anjos as seguintes linhas temáticas e características:

- rudeza materialista $X$ lirismo espiritual;

- ânsia de comunicação em monólogos de um solitário;

- inquietação filosófica;

- temática da morte;

- musicalidade e sonoridade;

- hermetismo e cientificismo.

Lúcia Helena (1977, p. 22) critica as avaliações que se fazem do autor à margem do poético, atestando-lhe esquizofrenia, angústia, ou apenas humor. A autora questiona os rótulos:

científico e exótico;

- obcecado pela imagem da morte e da putrefação;

- resultado de um caso patológico. (idem, ibdem p. 20).

A característica que ela prefere ressaltar diz respeito à sua linguagem que "reverencia o léxico repudiado pela estética do ‘belo’ (idem, ibdem p. 23).

Horácio de Almeida (1962, p. 1) em seu ensaio que apresenta uma análise psicológica do autor, apresenta a tradicional classificação: um materialista filosófico, e no decorrer do texto em que avança pelos dados psicossomáticos surge: um neurótico, um psicastênico (idem, ibdem p. 2), um "tipo excêntrico de pássaro molhado", um adolescente sorumbático (idem, ibdem p. 4).

Para Marcelo Backes (2001, p. 5) A. dos A. concilia a Filosofia e o Budismo, a Biologia e a Anatomia do Naturalismo de Haeckel. 
Sejam quais forem os estudos e em que época foram produzidos a concordância é de que Augusto dos Anjos não pode ser estudado em apenas uma direção e nem localizado em um só período. Esse trânsito não só é pacífico entre os que se aventuraram pela sua crítica, como também há o reconhecimento de que ele comunga com características que se opõem com radicalidade, muitas vezes num mesmo texto poético.

\section{A morte}

É freqüente encontrar A. dos A. denominado como o "poeta da morte". Dentre suas temáticas citadas com unanimidade encontra-se "a morte". Enfim, esse tema é pacífico dentre a crítica do poeta. O que muda é a maneira como cada análise lê esse tema em sua poesia.

Lúcia Helena (1977), discordando da idéia de “obsessão", defende que a morte é apenas mais um dos vários temas que fazem parte de seu universo temático, que ora aparece de maneira materialista, ora mais filosófica,

estas imagens obsessivas como as tem denominado a crítica (morte e putrefação) tem sido esparsamente detectadas, como um elemento que se pudesse destacar ou apenas privilegiar na poesia em questão. No entanto, nem são meros índices de uma obsessão pelo escatológico, pelo horrendo ou putrefato, nem são apenas imagens obsessivas. São imagens constitutivas, linhas de força dos eixos em que se elabora a visão cosmogônica do poeta. (HELENA, 1977, p. 22)

Já no estudo de Alexei Bueno (1994) a morte aparece como uma manifestação do pessimismo, como uma "implacável presença da maior das evidências da vida e do universo, [...] destruidora paciente e impiedosa de todos os esforços e devaneios humanos" (in: ANJOS,1966, p. 23). Bueno apresenta Augusto como o poeta da impotência e do fracasso, se deparando com "a mais absoluta e definitiva" forma de impotência e fracasso: a morte.

Seguem esta linha pessimista os fragmentos citados abaixo. Primeiro aquele que está na última estrofe d' "O poeta do hediondo", e que está também em sua lápide,

Eu sou aquele que ficou sozinho

Cantando sobre os ossos do caminho

A poesia de tudo quanto é morto! (“O poeta do hediondo”)

Morri! E a Terra - a mãe comum - o brilho,

Destes meus olhos apagou!... Assim

Tântalo, aos reais convivas, num festim

Serviu as carnes do seu próprio filho!

[...] ("Vozes de um túmulo") (ANJOS, 1994, p.330)

\section{0 pré-modernismo e Augusto dos Anjos}


É comum ler-se que o Pré-Modernismo é um período que não alcançou o status de escola literária, ficou apenas como um período de transição e que designa uma vasta produção literária dos primeiros 20 anos do século passado. Além disso, diz-se que não há um grupo de autores afinados em torno de um mesmo ideário, mas um conjunto de várias tendências e estilos literários. Sobrevivem produções de poetas parnasianos e simbolistas, prosadores naturalistas e realistas e surgem escritores que começavam a desenvolver um novo regionalismo e uma literatura crítica.

Neste período que, didaticamente vai de 1902 até a Semana de Arte Moderna, surgem experiências precursoras da linguagem modernista na poesia e na prosa e um nacionalismo consciente. Alguns textos utilizam-se de uma linguagem mais descontraída, que foge dos padrões gramaticais acadêmicos e adotam uma visão crítica, que ousava problematizar.

É Alexei Bueno (1994, p, 21), na introdução da poesia completa de A. dos A., quem traça os últimos anos do século XIX, "como o século por excelência do ufanismo científico, da euforia do conhecimento da ilusão do progresso ilimitado, criador de uma relativa onipotência do homem sobre a matéria".

Francisco de Assis Barbosa (1963, p.30), no estudo introdutivo da 29a edição de $E u$, o Rio de Janeiro, diz que "Augusto dos Anjos estava longe de ser o poeta da moda. Nem os poemas do $E u$ poderiam ser declamados nos salões, sob pena de provocar engulhos, vaias, risos. O poeta era inclassificável.”.

A época em que Augusto dos Anjos viveu, últimos anos do século XIX, foi um período de agitações populares e descoberta de um Brasil marginalizado, esquecido, miserável. Este Brasil de muitos contrastes passou a ser criticado, focalizando as regiões mais miseráveis e as classes mais sofridas. Alternaram-se neste período vozes intelectuais com vozes populares, a tradição da linguagem erudita de um Euclides da Cunha com o popularismo de textos de um Lima Barreto.

Este é o período histórico-literário quando do surgimento de $E u$, em 1912.

Nada regionalista, muito menos nacionalista e com uma linguagem que está distante de ser "descontraída", o que se visualiza das características da época pré-modernista na obra da qual estamos tratando é, no máximo, essa confluência de vários estilos e tendências e a presença de elementos do Cientificismo, do Evolucionismo e do "Monismo" (BUENO, in: ANJOS, 1966, p. 22) que caracterizava a Ciência na virada do século.

No entanto pode-se dizer que Augusto dos Anjos é um pré-modernista no sentido propriamente dito de "pré" moderno, ou seja, de antecipar características que serão exploradas 
pelo Modernismo. Essa modernidade percebe-se na inclusão de expressões até então inimagináveis em um texto poético.

\section{Um artista de difícil classificação}

A popularidade de Augusto dos Anjos é notória e se dá por motivos bem diferentes: ora pela musicalidade dos seus sonetos, ora pelas expressões tão estranhas à poesia, pertencentes ao universo científico, que a crítica chama de "anti-lirismo" e "mau-gosto".

A sonoridade relaciona sua poesia ao Simbolismo e demonstra o cuidado que o poeta tinha na colocação de cada expressão que faz parte de seus versos. Pode-se comprovar isso nas estrofes inicial e final do poema "Barcarola":

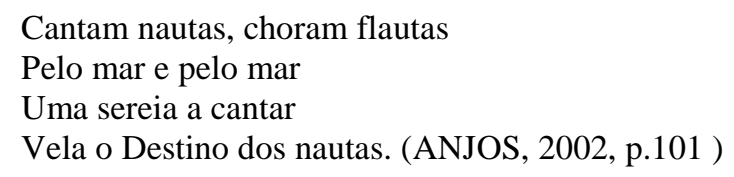

Essa sonoridade freqüentemente é quebrada pelo cientificismo e pela linguagem "apoética". Esses elementos aproximam-se com recursos literários e temática freqüentes no Naturalismo/Realismo, como em "Mistérios de um fósforo",

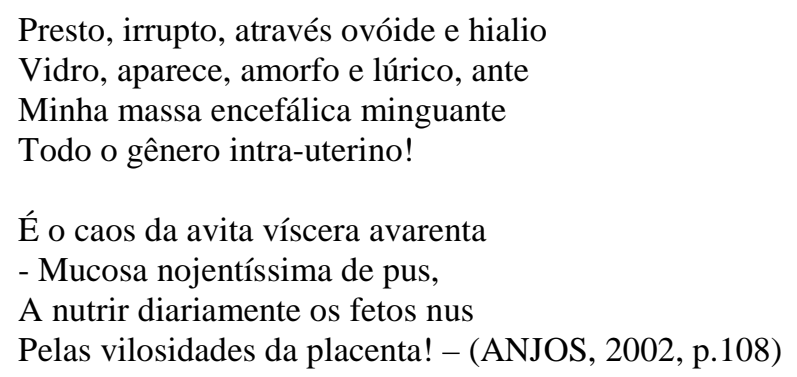

Este vocabulário cientificista aparece, no dizer de Cavalcanti (1986), "compensando" a popularidade. Já que se acreditava que a leitura fácil, decifrável por leitores comuns fosse sinônimo de baixa qualidade.

O uso do léxico cientificista é marcante sim, mas "estatisticamente muito pequeno em relação ao total de seu vocabulário" (BUENO, in: ANJOS, 1966, p. 22). O destaque que esta característica - assim como o uso de termos filosóficos, recebe talvez seja devido ao que Alexei Bueno (1966, p. 22) chama de "preguiça mental do leitor em relação a vocábulos que lhe causam estranheza e cuja utilização parece despropositada e inútill”.

As características formais da maioria da obra de Augusto dos Anjos aproximam-no do Parnasianismo, pois quase tudo o que escreveu, o fez em versos decassílabos. Alguns destes versos são compostos por apenas duas palavras. Sua técnica foi apurada e escolheu recursos de esmero e cuidado, como se pode ler no soneto "O poeta do Hediondo": 
Sofro aceleradíssimas pancadas

No coração. Ataca-me a existência

A mortificadora coalescência

Das desgraças humanas congregadas!

[...]

Quanto me dói no cérebro esta sonda!

$\mathrm{Ah}$ ! Certamente, eu sou a mais hedionda

Generalização do Desconforto. (ANJOS, 2002, p. 126)

Na obra $E u$, quarenta dos cinqüenta e seis poemas são sonetos. No entanto, não foram apenas poemas curtos que ele produziu, Augusto dos Anjos também é um poeta de produções longas, como é o caso do poema "Os doentes" que apresenta cento e dez quartetos divididos em nove partes.

A métrica é um identificador da poesia de A. dos A., mas o poeta não abandona a já citada musicalidade simbolista em seus decassílabos, que fazem de seus textos, "poesia para ser dita [...] declamáveis" (PROENÇA, 1980, p. 43), com ritmo cadenciado nas sílabas seis e dez, quatro e dez, exatamente como acontece nos versos 1 e 2 da primeira estrofe citada de "O poeta do hediondo". Rimas incomuns, de uma combinação surpreendente, marcam todos os seus poemas, quer sejam sonetos, quer sejam poemas longos. Dentre as rimas adotadas por Augusto dos Anjos, encontram-se expressões que têm a marca do cientificismo, herança naturalistas; expressões eruditas, herança parnasiana,

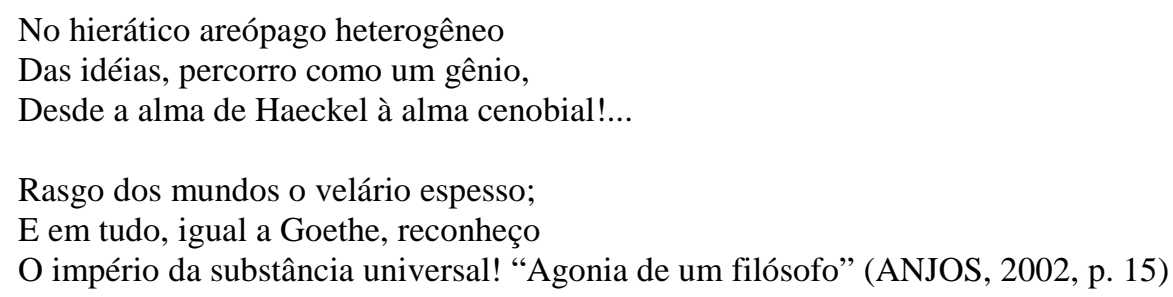

Conciliar opostos como "materialismo" e "espiritualismo" é, talvez, um dos motivos da inadequação de Augusto dos Anjos a uma só classificação de periodização e estilo literários. O trânsito entre o Simbolismo e o Parnasianismo - e seus "arredores", procura dar conta deste enquadramento, que Fischer (1994, p. 208) chama de "nada pacífico".

Augusto dos Anjos, aparentemente, é "um soneticista da poesia cientificista do realismo-naturalismo" (HELENA, 1977, p. 18), com ecos de simbolismo. Este comentário já concilia, pelo menos, três das várias correntes literárias que julgam algum contato com o poeta. É Lúcia Helena (1977, p. 18) que apresenta esse comentário, acrescentando que ele enfrentou inúmeros obstáculos e incompreensões. Dentre os autores citados no seu A cosmoagonia de Augusto dos Anjos, a autora cita Eduardo Portela, que insere o poeta "na encruzilhada entre o Pós (Romantismo) e o Pré (Modernismo), entre os estilos pósromânticos, parnasianos e simbolistas e os gestos ou formas antecipadores do Modernismo" (in: HELENA, 1977, p. 23. Grifo nosso). 
A modernidade de Augusto dos Anjos revela-se nesse ato de dessacralização até agora não compreendido: no âmbito de sua poesia dele reverencia o léxico repudiado pela estética do "belo". O vigor de sua linguagem se nutre d'essa necessidade de horroroso /que é talvez propriedade do carbono! (HELENA, 1977, p. 21)

Seguindo, pois, o pensamento modernista poderia se buscar na poesia de A. dos A. vínculos com a estética do século XX, tais como: desvincular-se da palavra poética, do compromisso com o "Belo" e dessacralizar o jargão romântico, ao utilizar os tão comentados termos "a-poéticos".

“Eu”, publicado em 1912, tem um caráter antecipador do movimento modernista. "Um diálogo com o novo tempo estético que se anuncia. Pluridimensional: veios românticos, parnasianos, simbolistas - um inusitado diálogo de confluências." (HELENA, 1977, p. 26). Sabe-se então que Augusto dos Anjos possui características de todas as escolas literárias da segunda metade do século XIX e essa mescla de tendências no mesmo objeto poético o torna, também, um poeta com tendências modernistas, mesmo tendo desaparecido em 1914 e tendo passado desapercebido pelos modernos.

O Modernismo aparece na inovação de adotar a abreviatura nos versos do soneto "Budismo Moderno",

Tome, Dr., esta tesoura, e...corte

Minha singularíssima pessoa. (ANJOS, 2002, p. 37),

na utilização de expressões que fazem parte da fala,

No auge de atordoadora e ávida sanha

Leu tudo, desde o mais prístino mito, (ANJOS, 2002, p. 80),

nas seqüências de frases nominais,

Meia-noite. Ao meu quarto me recolho.

Meu Deus! E este morcego! E, agora, vede: (ANJOS, 2002, p. 16),

na figura do índio visto não como um ser exótico, mas já colonizado e "vestido" com a cultura européia:

E o índio, por fim, adstrito à étnica escória,

Recebeu, tendo o horror no rosto impresso, (ANJOS, 2002, p. 50).

Esse achincalhamento do progresso aparece em "Os doentes"(ANJOS, 2002, p. 50) "que o anulava na crítica da História!"

Outra variedade de classificações do poeta aparece no estudo de Luis Augusto Fischer (1994, p. 208) que apresenta quatro possibilidades: Parnasiano pela opção pelo soneto, mas não pela impassibilidade; Determinista pela linguagem naturalista, mas não pela atitude filosófica; Simbolista pela "atitude filosófica dubitativa, algo mística" e, até Surrealista pela "vertigem" e pelas misturas aparentemente incompatíveis. 
Mas, apesar do conteúdo desviar do Parnasianismo, a forma não o faz. A. dos A. se utiliza muitas vezes da característica do "desfecho banal" (FISCHER, 1994, p.209), ao estilo de Alberto de Oliveira, ou ainda, do fechamento filosófico que Raimundo Correia tanto gostava de dar a sonetos seus como "As pombas" ou "Mal Secreto". Exatamente como acontece no primeiro verso da última estrofe do soneto "Morcego":

Meia-noite. Ao meu quarto me recolho.

Meu Deus! E este morcego! E, agora, vede:

Na bruta ardência orgânica da sede,

Morde-me a goela ígneo e escaldante molho.

[...]

A Consciência Humana é este morcego!

Por mais que a gente faça, à noite ele entra

Imperceptivelmente em nosso quarto! (ANJOS, 2002, p. 16)

A “chave-de-ouro" entra na seqüência de "cuidados formais notoriamente parnasianos" (FISCHER, 1994, p.210), o que ocorre no início do primeiro terceto de "Idealização da humanidade Futura":

Como quem esmigalha protozoários

Meti todos os dedos mercenários

Na consciência daquela multidão... (ANJOS, 2002, p. 19)

O "Monólogo da Sombra", longo poema que abre a obra $E u$, pode mostrar essa linguagem naturalista, que se repete na obra do poeta:

Com um pouco de saliva quotidiana

Mostro meu nojo à Natureza Humana.

A podridão me serve de Evangelho...

Amo o esterco, os resíduos ruins dos quiosques

$\mathrm{O}$ animal inferior que urra nos bosques

É com certeza meu irmão mais velho! (ANJOS, 1996, p. 195)

É Lúcia Helena (1977, p. 22) quem nos diz que o cientificismo que aparece na obra de Augusto dos Anjos não é usado num contexto técnico, como ocorria no seu surgimento, durante o Naturalismo, mas passa "conotativamente a denunciar a ciência transviada.".

Exemplo do Surrealismo, no início do poema "Os doentes", parte I, surge um "poemadelírio" (FISCHER, 1994, p. 211) sobre a cidade:

Como uma cascavel que se enroscava,

A cidade dos lázaros dormia...

Somente, na metrópole vazia,

Minha cabeça autônoma pensava!

Mordia-me a obsessão má de que havia,

Sob os meus pés, na terra onde eu pisava,

Um fígado doente que sangrava

E uma garganta órfã que gemia! (ANJOS, 2002, p. 45)

É Cavalcanti Proença (1980), na sua obra $O$ poeta do $E u$, quem apresenta um quadro classificatório onde esse trânsito continua. 
Manuel Bandeira em sua obra Apresentação da Poesia Brasileira, Andrade Murici, no Panorama do Movimento Simbolista Brasileiro e Oliveiros Litrento na obra Apresentação da Literatura Brasileira, como simbolista; Antônio Cândido e José Aderaldo Castelo na Presença da Literatura Brasileira, instalam esse autor numa fase transitória posterior ao Simbolismo; Já Afrânio Coutinho e Darcy Damasceno na obra A Literatura no Brasil, traduzem sua posição como um sincretismo e transição neo-parnasiano; Alfredo Bosi, nas obras A Literatura Brasileira e História Concisa da Literatura Brasileira apontam para as escolas Pré-Modernismo e Simbolismo; e por fim Luciana Stegagno em A Literatura Brasileira em um lugar que ela denomina do parnaso ao crepúsculo. Ana Miranda, a autora de A Última Quimera, romance publicado em 1995, lastreado por uma ampla pesquisa histórica a respeito da vida e obra de Augusto dos Anjos, apresenta também uma discussão a respeito da classificação da obra do jovem poeta. Sua discussão a respeito da classificação do poeta merece ser aqui registrada, mesmo em se tratando de uma obra de ficção, com trânsito pelo romance histórico, onde entrecruzam-se dados biográficos e históricos ou, no dizer de Eunice de Morais (1995, p. 459), “estas obras (A Última Quimera e Boca do Inferno) ilustram os romancistas da atualidade que, ao tratarem da história, são ficcionistas e historiadores que entram pelas fendas da história, aproveitando-se da liberdade do mundo ficcional para reescreverem fatos canonizados pela história.”.

O questionamento que uma das personagens da obra faz ao narrador de A Última Quimera é se a poesia de Augusto dos Anjos seria parnasiana, simbolista, cientificista ou romântica? O argumento usado na resposta são mais perguntas do que soluções,

como poderia ser simbolista, se era adepto da racionalidade? Como poderia ser romântico, se ele era tão realista? O professor diz que os temas de Augusto são românticos hugoanos, nem todos, na verdade apenas alguns, o que não é suficiente para enquadrá-lo no romantismo. 'Seus decassílabos são construídos de maneira parnasiana', diz ele. Mas sua morbidez egoística é exatamente oposta à salutar impessoalidade parnasiana. Tampouco a palavra cientificista é suficiente para explicar Augusto, uma vez que ele insinua todos os sentimentos, e sua poesia é doada de uma subjetividade filosófica. (MIRANDA, 1995, p. 260)

A discussão não apresenta resposta, mas caminhos. Se há um vínculo da sua obra à filosofia, é preciso lembrar que o próprio romance já o faz: "a filosofia é o espírito da ciência" (Idem, ibidem p. 260), mas também contra-argumenta dizendo que para que se seguisse este argumento, todos os poetas, de todos os tempos, seriam enquadrados com cientificistas, pois a poesia apresenta os fenômenos da natureza, as leis da existência, enfim o "Universo, a história, a vida" (idem, ibidem p. 260).

Augusto dos Anjos é um poeta controverso que não é irregular; é um autor inclassificável que não é um fora de seu tempo; Ele tem tantas faces que poderia ter 
ultrapassado várias décadas de leitura, estudo e produção e, no entanto, não passou do trigésimo primeiro aniversário. Ler Augusto é transitar do Romantismo ao Modernismo, passando por todas as correntes estéticas intermediárias. É um poeta que conseguiu colocar em verso, e em uma única obra, a essência de tendências as mais díspares, sem ser hermético nem incompreensível.

\section{Referências}

ALMEIDA, Horácio de. As Razões da Angústia de Augusto dos Anjos, RJ: ed. $\quad$ Gráfica $\quad$ Ouvidor, $1962 . \quad$ Disponível em:http://www.revista.agulha.nom.br/augusto16a.html. Acesso 28 de jul. de 2006.

ANJOS, Augusto. Eu e outras poesias. Porto Alegre: L\&PM, Coleção L\&PM Pocket, 2002, v.148.

BACKES, Marcelo. Prefácio. In: ANJOS, Augusto. Eu. Porto Alegre: Mercado Aberto, 2001.

BARBOSA, Francisco de Assis. Estudo Introdutivo. In: Eu. 29. ed. Rio de Janeiro, 1963.

BUENO, Alexei (org.). Augusto dos Anjos. Obra Completa. Rio de Janeiro: Nova Aguilar, 1994.

FERREIRA, Nadiá Paulo. Crítica Literária e Psicanálise. In: SAMUEL, Rogel (Org). Manual de teoria literária. Petrópolis: Vozes, 1984.

FISCHER, Luis Augusto. Augusto dos Anjos: surrealista. Organon, Porto Alegre, v. 8, n. 22, 1994.

HELENA, Lúcia. A Cosmoagonia de Augusto dos Anjos. Rio de Janeiro: Tempo Brasileiro, 1977.

MIRANDA, Ana. A última quimera. São Paulo: Cia das Letras, 1995.

MORAIS, Eunice. Ana Miranda. Dias e dias. Revista Letras, Curitiba, n. 60, p. 457-459, jul./dez. 2003. Editora UFPR 457. Disponível em: http://calvados.c3sl.ufpr.br/ojs2/index.php/letras/article/viewFile/2878/2360. Acesso em 27 de jul. de 2006.

OLIVEIRA, Vanderléia da Silva. A (des) construção do cânone pela ficção em A Última Quimera, de Ana Miranda. Disponível em: http://www2.unopar.br/pesq_arq/revista/HUMANAS/00000093.pdf . Acesso em 27 de jul. de 2006.

PROENÇA, Ivan Cavalcanti. O poeta do eu: um estudo sobre Augusto dos Anjos. 3.ed. Rio de Janeiro: José Olympio, 1980. 